\title{
The upcoming revolution in ultrasonic guided waves
}

Joseph Rose

Joseph L. Rose, "The upcoming revolution in ultrasonic guided waves," Proc. SPIE 7983, Nondestructive Characterization for Composite Materials, Aerospace Engineering, Civil Infrastructure, and Homeland Security 2011, 798302 (15 April 2011); doi: 10.1117/12.897025 Health Monitoring, 2011, San Diego, California, United States 


\title{
The Upcoming Revolution in Ultrasonic Guided Waves
}

\author{
Joseph L. Rose \\ Penn State University \\ ilr9@psu.edu \\ and FBS, Inc., State College, PA \\ jrose@fbsworldwide.com
}

\section{Introduction}

This paper will include discussions on fundamental principles and market forces associated with the upcoming revolution in ultrasonic guided waves. A literature survey is also outlined covering some selected major developments this past decade. A few applications in pipe, rail, bonding and composites, imaging and tomography, ultrasonic vibration, de-icing, structural health monitoring, gas entrapment, and non-linear methods are treated to provide an idea of where we are heading with ultrasonic guided waves.

\section{Market Forces:}

Ultrasonic Guided Wave integration into NDE and SHM is growing rapidly for a variety of reasons. Quite often it is the only way to solve a problem because of limited access to a structure and the ability to inspect a large area from a sensor at only a single location on the structure. Ultrasonic guided waves are very different from the more standard ultrasonic bulk wave inspection where hundreds of test modes become possible, whereas for bulk waves only two modes of inspection are possible, longitudinal and shear. With the initiation of guided wave inspection taking off around 15 years ago, there was high expectations on use which was subsequently held back because of a lack of theoretical understanding and weakness in computational power required in modeling analysis. In technology transfer from laboratory to field, we often encountered many challenges of coatings, hidden, buried structures and geometrical intricacies in environment, etc. Many of their problems have now been overcome and technology transfer and product development are moving rapidly forward. Guided wave innovation is amazing in application, sensitivity and penetration power. Some of these advancements are discussed on these pages.

Taking place is a paradigm shift from bulk wave ultrasonics to guided waves because of reduced cost, less inspection time and greater coverage, and the ability to solve new problems with no prior solution potential.

There is also a paradigm shift from NDE to SHM because of improved reliability, continuous screening, and early warning of defect growth and structural failure. As a result, there is baked in potential for prefab sensor installation. There are also many cost and safety benefits associated with SHM. 
Expectations for market growth are focused on new markets and not necessarily replacement in the bulk wave market. From discussions with many users, funded research, and number of publications, up to $20 \%$ of the current bulk wave market could be replaced with an expansion in new SHM and NDE markets which could expand by $35 \%$ over the next decades compared to the current ultrasonic bulk wave market. In fact, the anticipated growth rate for NDE, SHM and ultrasonic guided wave services could be about $10 \%$ per year starting in 2020. Reasons for growth can be associated with improvements in guided wave application and innovation in new product development programs with integration into wireless and energy harvesting systems. Instead of tens of specialized guided wave products, guided wave product trends are directed towards custom to configurable, easier to use, lightweight, speed, and improved coverage. More transparency is also becoming possible with improved software so that training becomes simpler and straight forward

The future looks bright for ultrasonic guided waves in NDE and SHM with applications in pipe, rail, bridge, aircraft, power plants, processing plants, highways, buildings, and in almost any government or industrial facility.

\section{Literature Survey}

Many textbooks are available on the subject of ultrasonic guided waves. For example, in 1975, Graff 's book covers waves in infinite media and in various waveguides [1]. Rose's book 1999 [2] covers fundamentals including dispersion curves, wave structure, source influence and excitability. Fundamentals of wave propagation are presented nicely by Achenbach (1973), Auld (1973), and Datta (2008) [3 5]. In Achenbach 2003, some interesting reciprocity concepts associated with guided and Lamb waves are treated [6]. A recent book that highlights some interesting aspects of guided waves in composite materials is presented by Rokhlin, Chimenti, and Nagy [7].

Zhu and Rose 1999 employs boundary element methods (BEM) and simulation [9] for guided wave analysis. Rose 1994 also covers wave mechanics principles [8] and Gao et al. 2010 [10] introduces the concept of goodness curves to assist in mode and frequency selection in studying such features as skew, a variety of wave structure variables, excitability, etc. Yan et al 2010 [11] uses ultrasonic guided wave mode and frequency selection for defect detection and characterization in a multilayer hybrid laminate. Fromme and Sayir 2002 studied the detection of cracks at rivet holes using guided waves [12]. Rizzo et al in 2009 studied fatigue crack detection in waveguides [13]. Ing and Fink in 1998 introduced time reversal techniques [14].Wilcox in 2003 employed rapid signal processing techniques to remove the effect of dispersion from guided wave signals [15].

\section{Pipe}

Ultrasonic guided waves were first introduced to tubing inspection by Rose et al 1993 [16]. Following the research results of Ditri and Rose (1992) [17], Li and Rose developed an analytical method to simulate the angular profiles in hollow cylinders [18]. In 2002, Li and Rose presented the phased array focusing technique for longitudinal guided waves propagating in cylindrical shells [19]. Rose and Mudge introduced 
a commercial application of the guided wave focusing technique with a pipeline inspection tool, the Teletest-focus instrument[20]. Sun et al. 2003 carried out the angular profile calculations and the phased array focusing technique for torsional guided wave propagation in hollow cylinders [21]. If the angular profiles show that ultrasonic energy is naturally concentrated at a circumferential location at a particular propagation distance, this phenomenon, which is called "natural focusing," can be used to improve pipeline inspection $[22,23]$.

Circumferential waves were studied by Thompson, et al. who used Lamb waves for steel plate and pipe inspections in 1972 [24]. Van Velsor et al. 2009 developed enhanced coating disbond detection methods with guided wave physically based features[25].

Defect imaging and synthetic focusing methods were introduced by Hayashi et al. 2005 [26], Mu and Rose 2008 by focusing [27], and with coatings [28], Davies and Cawley 2009 [29], Mu et al. 2010 [30], and Velichko and Wilcox 2009 with post-processing [31].

Pavlakovic et al. in 1997 introduced a commercial software package for dispersion curve calculation: DISPERSE [32]. Demma et al. in 2001 studied mode conversion of longitudinal and torsional guided modes due to pipe bends [33]. Ma et al. in 2007 studied sludge and blockage detection inside pipes [34].

SAFEM efficient computational techniques were introduced for guided wave problems by Hayashi et al. 2002 [35]. Magnetostrictive methods were pioneered by Kwun et al. in 1998 covering guided wave inspection of pipe using magnetostrictive sensors [36]. Kim et al. in 2005 used magnetostrictive transducers with ferromagnetic strips $45^{\circ}$ from the axis of a pipe [37].

\section{Rail}

Grewal 1996 used Rayleigh waves in rail [38]. Hayashi et al 2003 computed guided wave dispersion curves for a bar with an arbitrary cross-section with a rod and rail example [39]. Wilcox et al 2003 also introduced some interesting aspects of rail inspection [40]. Gunawan and Hirose in 2005 used boundary element analysis of guided waves in a bar with an arbitrary cross-section [41]. Bartoli et al. (including Lanza di Scalea) in 2006 employed modeling aspects of wave propagation in damped waveguides of arbitrary crosssection [42]. Lee et al. 2009 used a guided wave approach for defect detection under shelling in rail with wave structure selection examples for sensor design to achieve special effects [43].

\section{Bonding \& Composites}

Mal et al. in 1988 and 1990 studied guided wave evaluation of adhesive bonds [44]. Chimenti et al. in 1988 made use of guided waves reflection and propagation in fluid-coupled composite laminates [45]. Datta et al. in 1990 studied edge and layering effects of guided waves in a multilayered composite plate [46]. Na (2002) researched ultrasonic guided waves for steel bar concrete interface testing [47]. Hosten and Castaings in 2005 employed finite elements method (FEM) for modeling the guided waves propagation in structures with weak interfaces [48]. Puthillath and Rose 2010 introduced higher order ultrasonic guided wave inspection of a titanium patch that was bonded to an aluminum aircraft skin [49]. 


\section{Phased array for plates}

Li and Rose (2001) implemented guided wave mode control by use of a phased transducer array [50]. Giurgiutiu et al. in 2002 invented a virtual beam steering technique by using PZT transducer arrays [51]. Wilcox in 2003 developed omni-directional guided wave transducer arrays for rapid inspections of large areas in plates [52]. Yan and Rose in 2007 used beam steering in composites [53] and in 2009 with a phased array time delay comb [54]. Salas and Cesnik in 2010 presented guided wave structural health monitoring (SHM) by using composite long-range variable-length emitting radar (CLoVER) transducers in composite materials [55]. Senesi et al. in 2010 developed guided wave frequency-steerable arrays for SHM[56].

\section{Guided wave imaging and tomography}

Hinders et al. in 1999 studied Lamb wave tomographic scanning [57] and Gao et al. in 2005 introduced guided wave mode and frequency selection for tomography for aircraft structures [58]. Breon et al. in 2007 did guided wave damage detection tomography for SHM in pipeline elbows [59] and Van Velsor et al. in 2007 studied pipe defects by employing guided wave tomography technique [60]. Yan et al. in 2010 also used ultrasonic guided wave imaging techniques in SHM [61].

Some research has been carried out to improve the guided wave imaging techniques. Ruzzene in 2007 employed frequency wave number domain filtering for improved damage visualization [62]. Hall and Michaels in 2011 studied computational efficiency of ultrasonic guided wave imaging algorithms [63].

\section{Ultrasonic vibration}

Rose et al. in 2010 introduced an ultrasonic guided wave modal analysis technique(UMAT) for defect detection [64], followed by work by Yan and Rose (2010) [65].

\section{Deicing}

Venna et al. 2007 [66], Zhu et al. 2008 [67], and Gao et al. 2009 [68] utilized ultrasonic guided waves for deicing experiments.

\section{$\underline{\text { SHM }}$}

Michaels et al. in 2004 used feature-based classifiers for ultrasonic SHM [69]. Raghavan and Cesnik in 2004 modeled use of piezoelectric-based Lamb wave generation and sensing for SHM [70].

\section{Nonlinear}

Nonlinear methods are now finding applications in ultrasonic guided wave analysis. See Cantrell et al. 2001 [71], Kim at el. 2006 [72], and Pruell et al. 2009 [73]. 


\section{Fundamentals}

A comparison of ultrasonic bulk waves with ultrasonic guided waves is illustrated in figure 1. Note that bulk waves cover only a small localized section of a structure. Scanning is necessary to complete an inspection of a test part. The ultrasonic guided wave floods a large area from a single probe position. Two basic guided wave excitation examples includes angle-beam excitation and comb excitation as illustrated in figure 1. A more detailed comparison is presented in table 1.
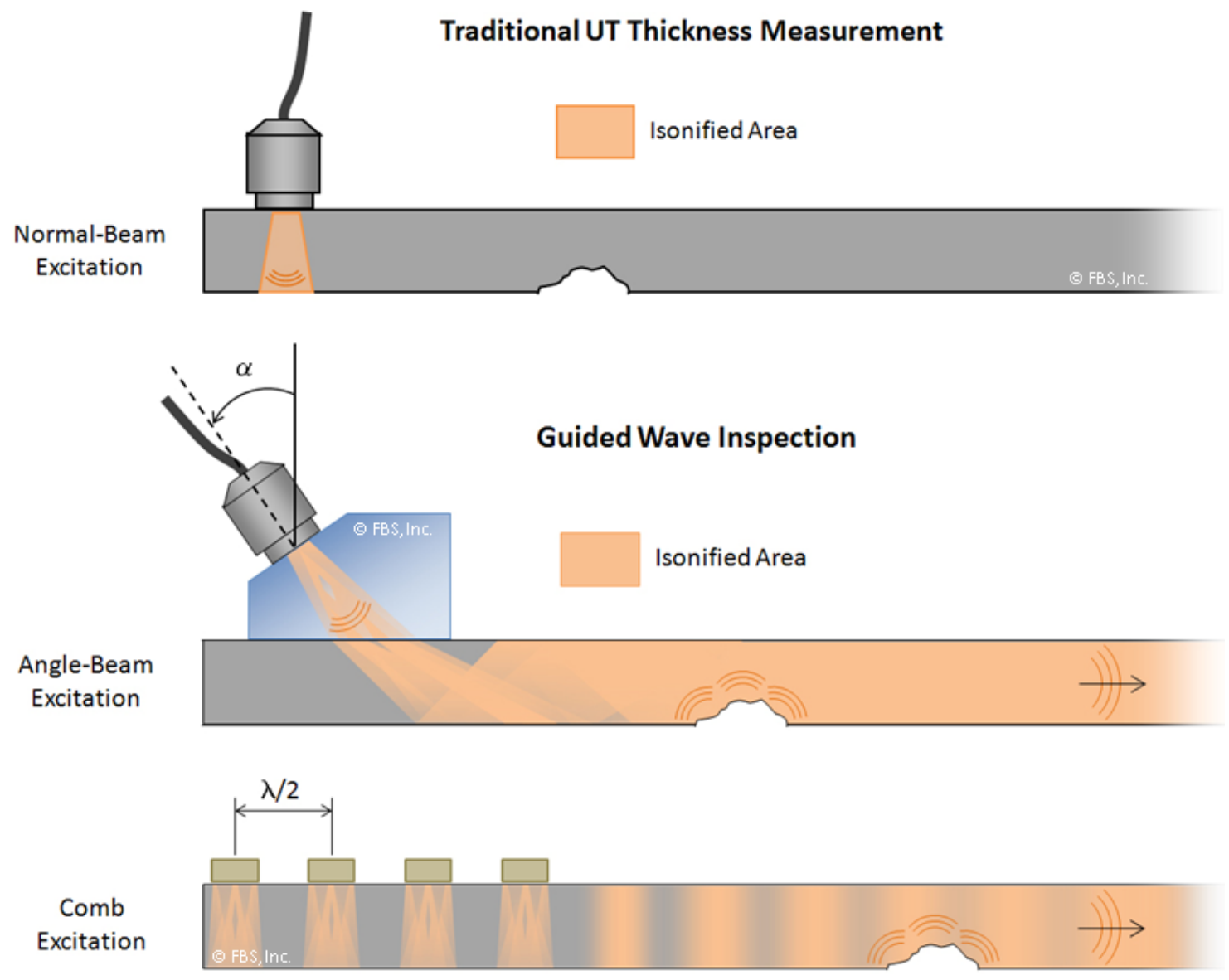

Figure 1

Comparison of Ultrasonic Bulk and Guided Waves

Ultrasonic guided waves can be used to inspect almost any structure since the structures fall into a class of natural wave guides. See table 2. Again, widespread adaptation of guided waves has just occurred because of improvements in understanding and in signal interpretation. A special challenge, however, is on thick sections, but even here, surface waves can be used to inspect regions close to the surface of a structure. Frequency changes can increase the depth of penetration and hence improve the examination of a structure. 
Table 1

A Comparison of the Currently Used Ultrasonic Bulk Wave Technique and the Ultrasonic Guided Wave Inspection Procedure

\begin{tabular}{|c|c|}
\hline Bulk Wave & Guided Wave \\
\hline Tedious and time consuming & Fast \\
\hline Point by point scan (accurate rectangular grid scan) & Global in nature (approximate line scan) \\
\hline Unreliable (can miss points) & Reliable (volumetric coverage) \\
\hline High level training required for inspection & Minimal training \\
\hline Fixed distance from area of concern required & Any reasonable distance from defect acceptable \\
\hline Defect must be accessible and area seen & Defect can be hidden \\
\hline
\end{tabular}

Table 2

Natural waveguides

- Plates (aircraft skin)

- Rods (cylindrical, square, rail, etc.)

- Hollow cylinder (pipes, tubing)

- Multi-layer structures

- Curved or flat surfaces on a half-space

- Layer or multiple layers on a half-space

- An interface

The many exciting benefits of ultrasonic guided waves are depicted in table 3 . These reasons have propelled the development of guided waves forward. Site preparation for inspection is greatly reduced as a result of large coverage of hidden sections of a structure.

Table 3

Principal Engineering Benefits of Guided Waves

Inspection over long distances from a single probe position.

$>$ Ability to inspect hidden structures and structures under water, coatings, soil, insulations, and concrete.

$>$ Cost effectiveness because of inspection simplicity and speed 
Major differences between NDT and SHM are highlighted in table 4, the most crucial of which is the requirement of a baseline in SHM. Very complex structures can be studied with SHM that are not even approachable with NDT. Baseline information can change however, and such items as temperature and boundary condition compensation are being studied.

Table 4

The major differences between NDT and SHM

NDT

- Off-line evaluation

- Time based maintenance

- Find existing damage

- Baseline generally not
available
SHM

- On-line evaluation

- Condition based maintenance

- Determine fitness-forservice and remaining useful time

- Starts with a Baseline on initial data collection

Let us now consider some aspects of wave mechanics associated with guided waves. For every wave guide there is a unique set of phase velocity dispersion curves as shown in a sample problem for a plate. Group velocity dispersion curves can be calculated from the phase velocity dispersion curves. Attenuation dispersion curves can be calculated from computed complex roots in the eigen value problem. See Rose [2] for example. For every point on the dispersion curve there is a corresponding wave structure that is a special distribution across the thickness of the structure of such variables as in-plane displacement and out of plane displacement, as shown in a sample result in figure 2. Note for example, that if the outer surface has dominant out of plane displacement, a water loaded plate would lead to ultrasonic energy leakage into the fluid. On the other hand, if the outer surface had only in plane displacement, the ultrasonic guided wave energy propagating in the plate would not see the fluid. Other variables like shear stress, normal stress, or energy could also be considered. In fact, the key to success in ultrasonic guided wave experiments is associated with a wise choice of mode and frequency on the dispersion curve. The experimental ability to get onto a dispersion curve is possible by using a comb activation line or angle beam activation line as demonstrated in figure 2. To do this, of course, sufficient frequency bandwidth is required to be successful. A further challenge is trying to select a proper mode and frequency is delineated in figures 3 and 4 . Because of the excitation transducer's source influence (size and vibration pattern) there will be a 
phase velocity spectrum along with the frequency spectrum. The activation region in the phase velocity dispersion curve space is quite large; hence many modes and frequencies are generated at the same time. See [2]. Note in figure 4, the presence of side lobes in the phase velocity spectrum. Hence propagation of a single mode is difficult, often including other nodes possibly with different group velocities. The noisy signals are of a coherent variety and not random, often leading to difficulties for the inspector. Proper sensor design and narrow band frequency content can improve the result.

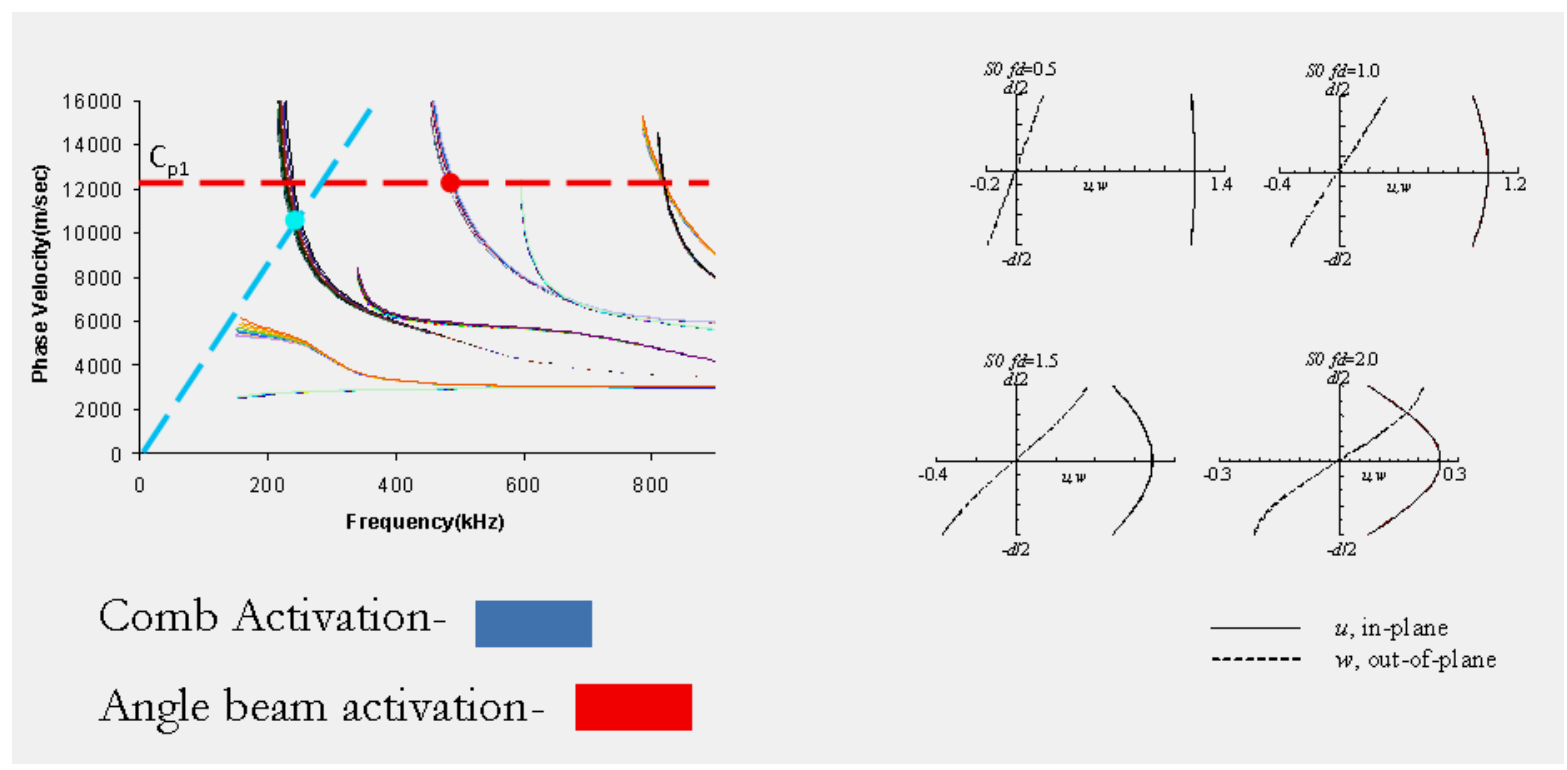

Figure 2

Activation and wave structures 


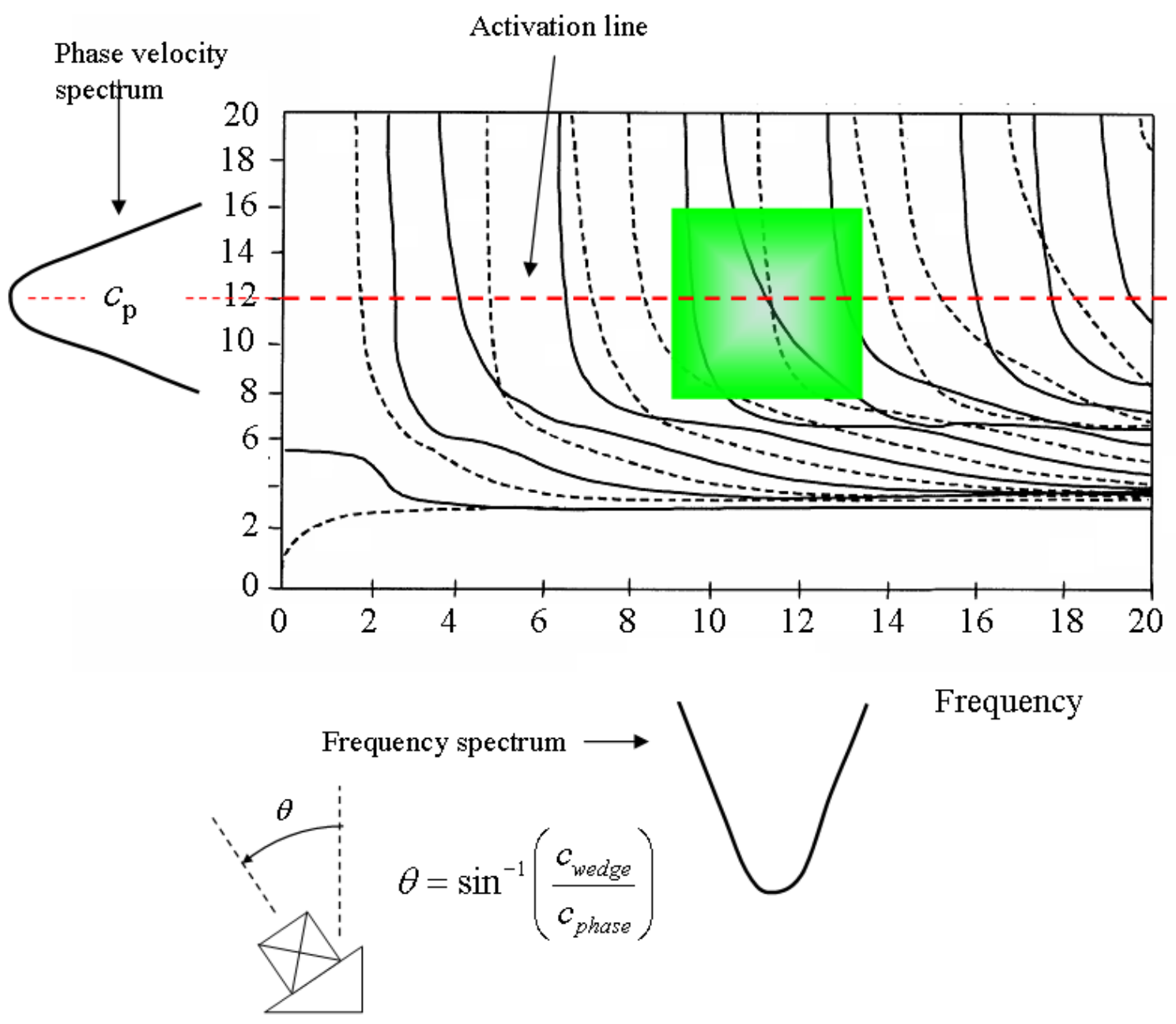

Figure 3

Source influence for a typical angle beam excitation or an ability to generate a specific mode and frequency

We will now consider the modeling analysis component associated with the understanding of ultrasonic guided waves. The approach makes use of a hybrid analytical FEM computation as exhibited in figure 5. The FEM computation process is useless unless proper boundary conditions are considered in a simulation of an ultrasonic guided wave inspection. The boundary condition comes from a sensor design that comes from a choice of appropriate wave structure from the phase velocity dispersion curve space, hence an appropriate mode and frequency choice to solve a particular problem is NDE or SHM. 


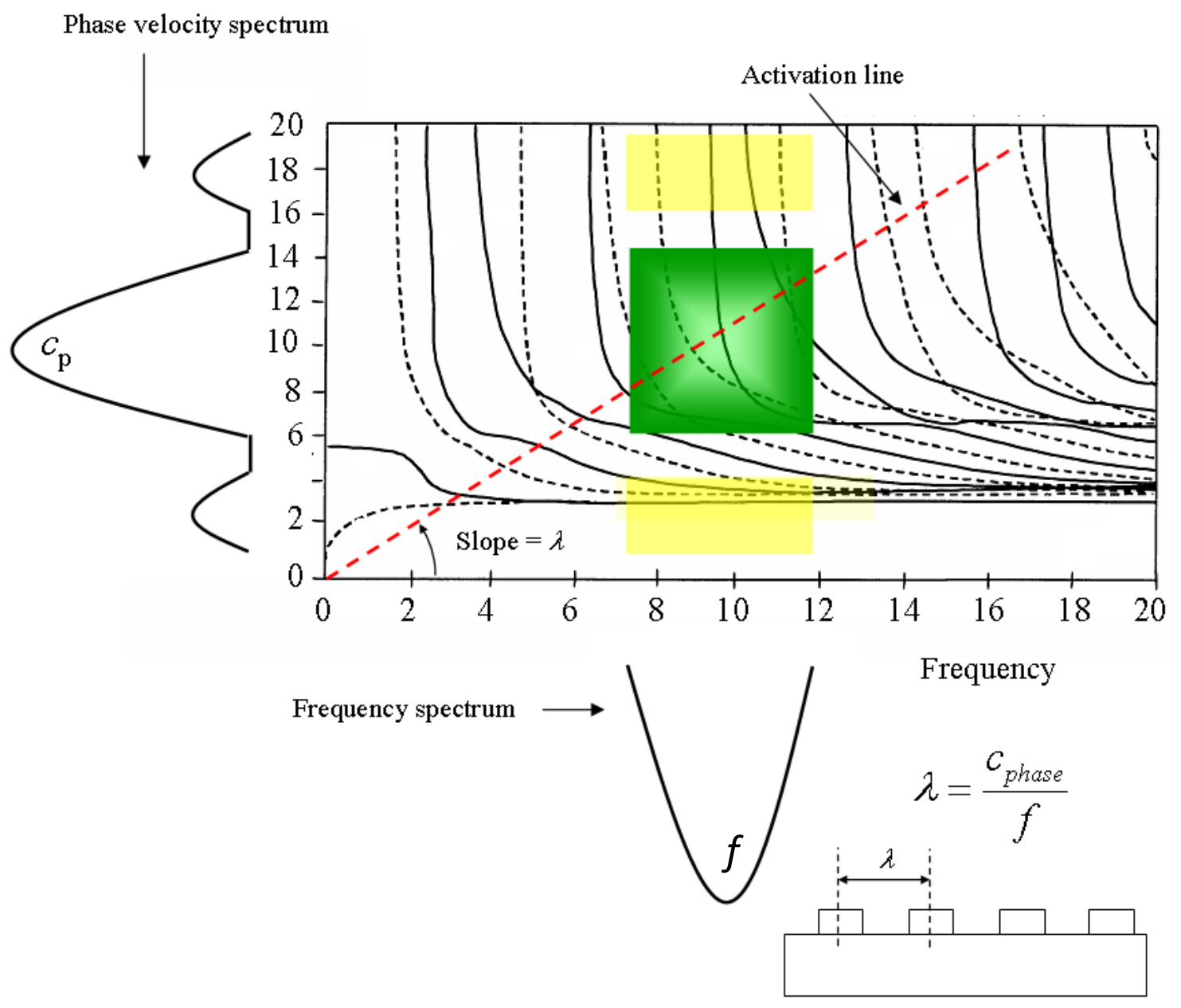

Figure 4

Source influence of a typical comb transducer excitation or an ability to generate a specific mode and frequency

A few sample problems that have been solved using the hybrid analytical FEM computation are listed in table 5 along with appropriate references. 


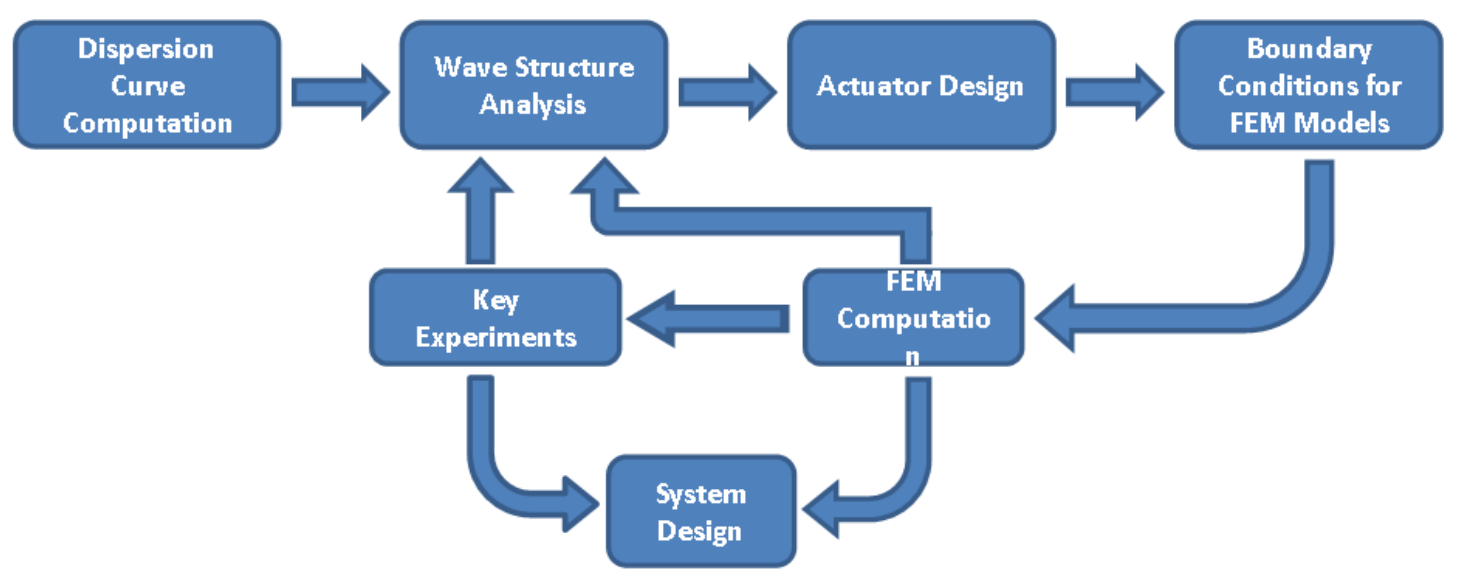

Figure 5

The Hybrid Analytical FEM Approach for Solving Guided Wave Problems

Table 5

Examples of the use of the Hybrid Analytical FEM

Approach for solving guided wave problems

Rail - transverse cracking under shelling, defect in base (Lee et al [43])

$>$ Adhesive Bonding - weak interface (Puthillath, [49])

$>$ Water Loaded Structure - to avoid false alarms (Gao et al [58])

$>$ Gas Entrapment - leaky and non leaky waves (Rose [2])

$>$ De-icing - maximum shear stress at the interface (Zhu et al [67])

$>$ Piping - flexural mode best selection for focusing (Sun et al [22] 
Phased array systems have risen to ecstatic heights in the NDT field for ultrasonic bulk waves because of electronic beam scanning with one transducer array compared to manual scanning with many different angle beam probes. Laid out in figure 6 is the historical progression of phased array development from the 70 's to current day developments. Just recently, phased arrays for real time and synthetic focusing in practical pipe inspection applications have been introduced by Rose and Mudge [20]. Even more recently phased arrays for plate inspection were introduced by Li and Rose [50] and Giurgiutiu and Bao [51].

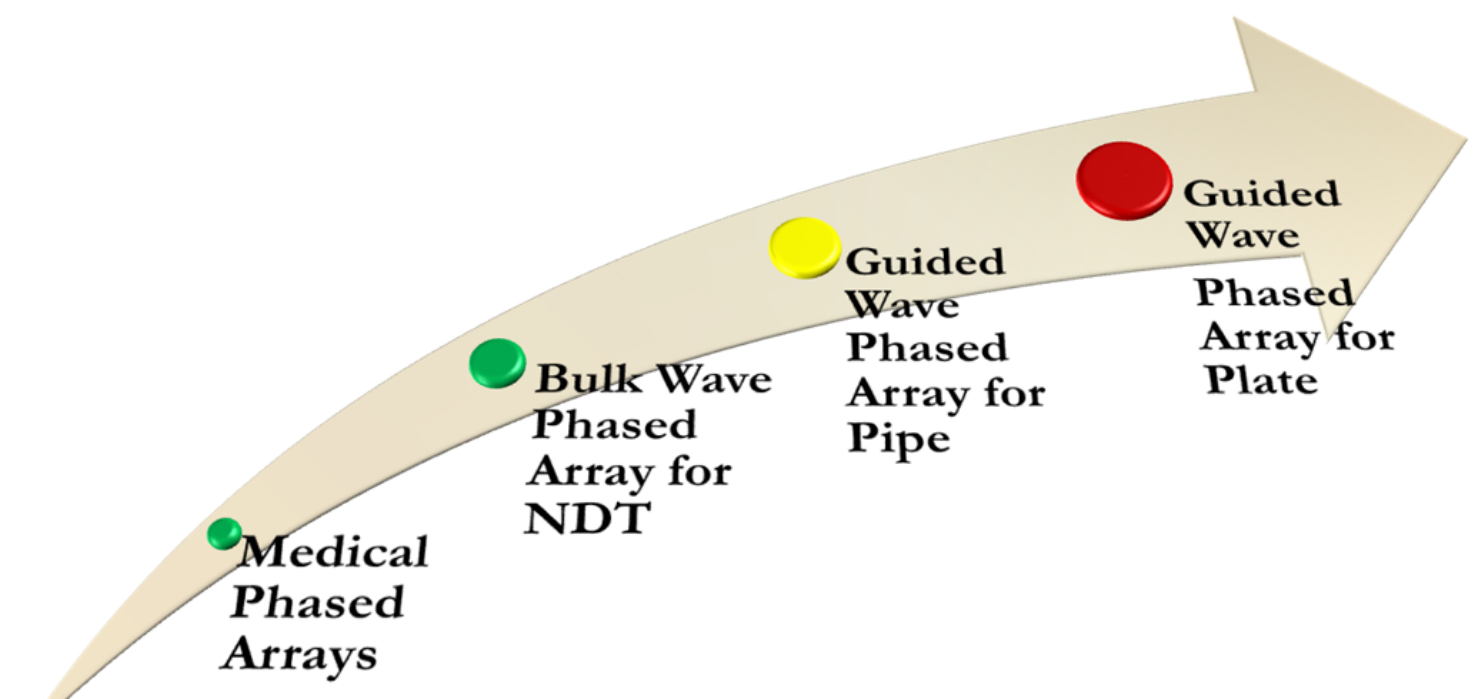

Figure 6

Guided wave phased array technologies

\section{Applications}

\section{Pipe}

Static shot FEM simulations, at different times of an axisymmetric guided wave propagation in a pipe are demonstrated in figure 7. To go beyond the axisymmetric wave to focusing considerations, the methods of focusing are listed in table 6 . A static shot example of a real time phased array result is illustrated in figure 8. Notice the achievement of the focal spot in the $5^{\text {th }}$ frame. The focal spot can be changed in size by changing the probe and instrument design parameters. The focal spot can then be moved anywhere axially and circumferentially in the pipe. The benefits of focusing are described in table 7. 
A sample experiment is presented here in figures 9 and 10 where all three of the defects shown in figure 9 are found and presented in figure 10. The upper diagram shows an FFA plot over a frequency range from 20 to $80 \mathrm{KHZ}$ showing that defect detection sensibility is a function of frequency. The FFA plot shows the best frequency to see each defect. Each defect could have a different preferred frequency in its reflection characteristics. The second trace is a video envelope of the RF waveform clearly showing the defects and welds in the structure. The third trace shows a pipe laid out flat with an image of the defect locations both axially and circumferentially. Excellent results were obtained.

To illustrate the focusing principle in a practical sense, consider the partial loaded field natural focusing result as calculated in figure 11 . The loading transducer is centered at zero degrees. With the pipe laid out flat it can be seen that the natural focal spot in this example occurs at the opposite side of the pipe at 180 degrees at an axial location of around 10 meters. If we were to have an angular profile due to some partial loading around the circumference at some axial position as shown in figure 12a, and if we were to arrange a series of partial loadings around the circumference and phase them properly, we could end up with a superimposed result at the same axial distance with a strong focal point as plotted in figure $12 \mathrm{~b}$. Two focused experimental results are diagrammed in figure 13 . These profiles provide confidence in a call that a defect is indeed there and its' circumferential position can be clearly determined.

Wave propagation into a pipe elbow and beyond can create blind spots at a specific frequency due to mode conversion. Pipe coating and buried pipes can also seriously reduce penetration distances. See Rose [74] for successes and challenges in pipe inspection.

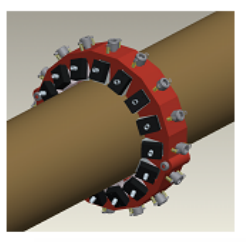

Transducer array located at pipe end Axisymmetric loading, no time delay applied

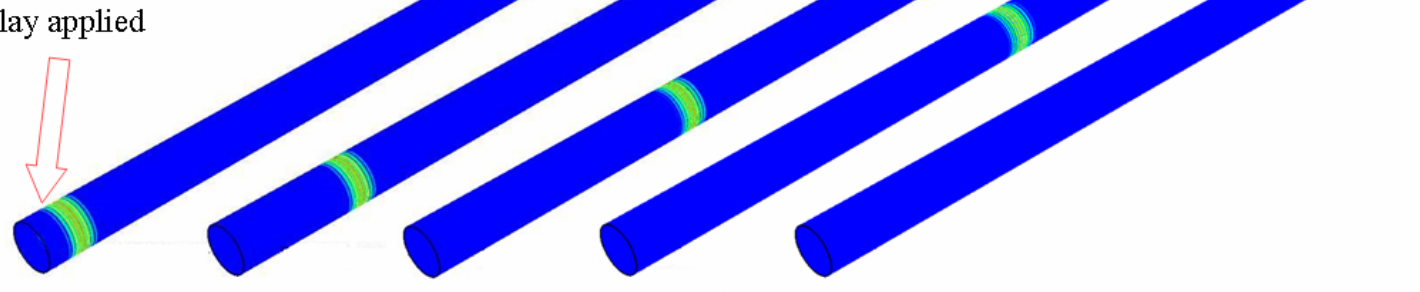

Figure 7

Axisymmetric guided wave propagation along the pipe 
Table 6

Guided wave pipe focusing techniques

-Frequency tuning

axisymmetric excitation and receiving

- Natural focusing

partial loading excitation and receiving

-Phased array focusing

multi-element array excitation and receiving with time delay and amplitude tuning

Transducer array located at pipe end

Array can be segmented into 4 or 8 channels.

Time delays are applied.

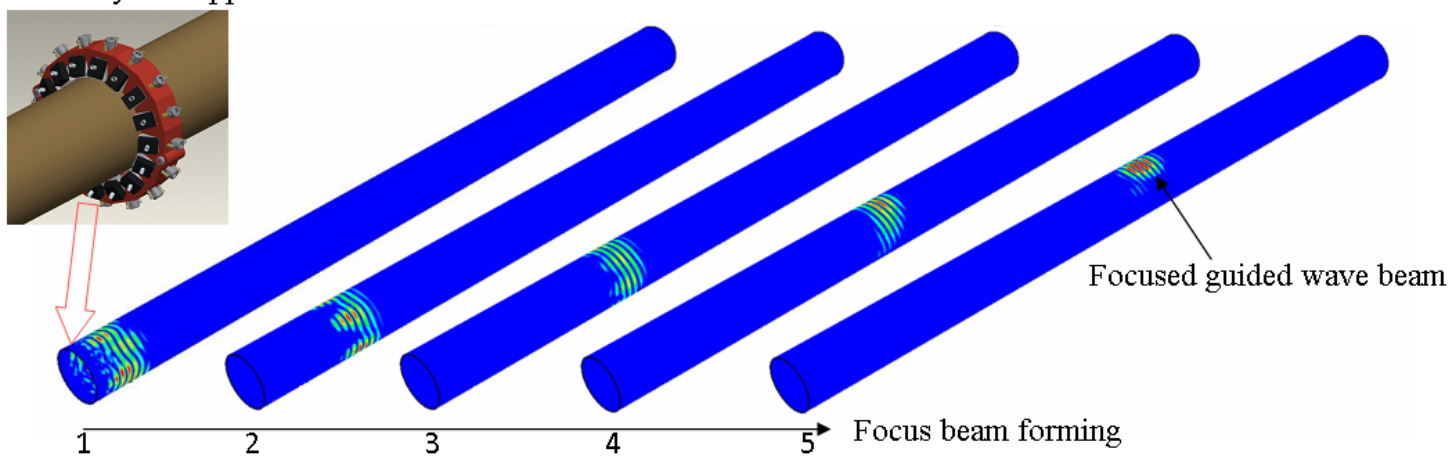

Figure 8

Guided wave active focusing in pipe FE simulation results 


\section{Table 7}

\section{Focused Guided Wave Inspection}

- Improved defect probability of detection (approximately 3\% CSA, compared to $9 \%$ for axisymmetric)

- Decreased defect false alarm rate

- Increased inspection confidence

- Improved penetration power for coated pipe

- Excellent defect circumferential location analysis

- Improved signal to noise ratio compared to axisymmetric

- 6 to infinite $\mathrm{dB}$ improvement compared to axisymmetric

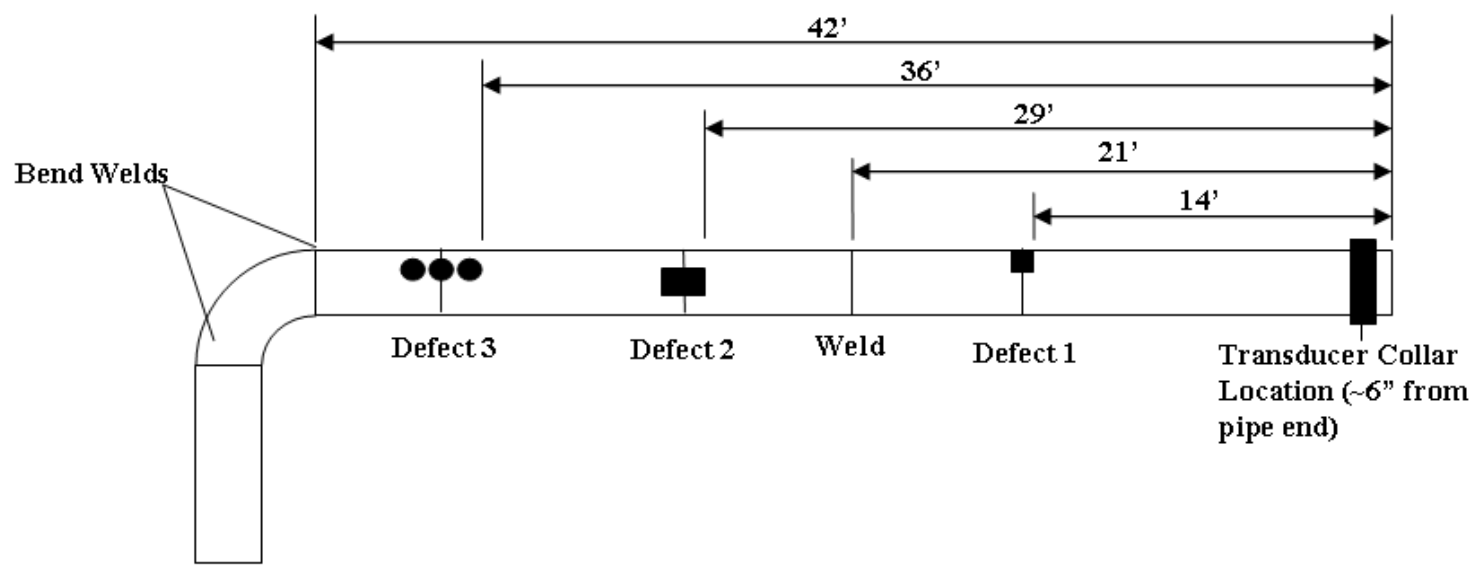

Defect 1 - $0^{\circ}$

$\sim 3$ 'x3" Blend Out

$50 \%$ Max Wall Loss

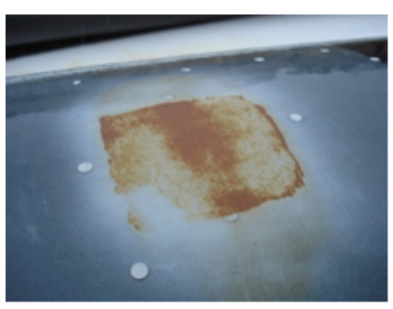

Defect $2-270^{\circ}$

$\sim 4$ 'x4" Blend Out

50\% Max Wall Loss

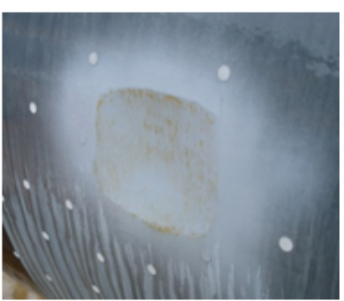

Defect $3-315^{\circ}$

Three Flat Bottom Holes

1 " Diameter, Depth=60\%

Spacing between holes $=1 \mathrm{ft}$.

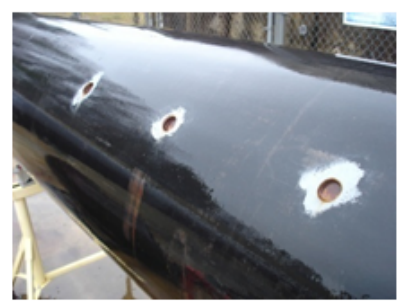

Figure 9

Details of a pipe section that was studied 

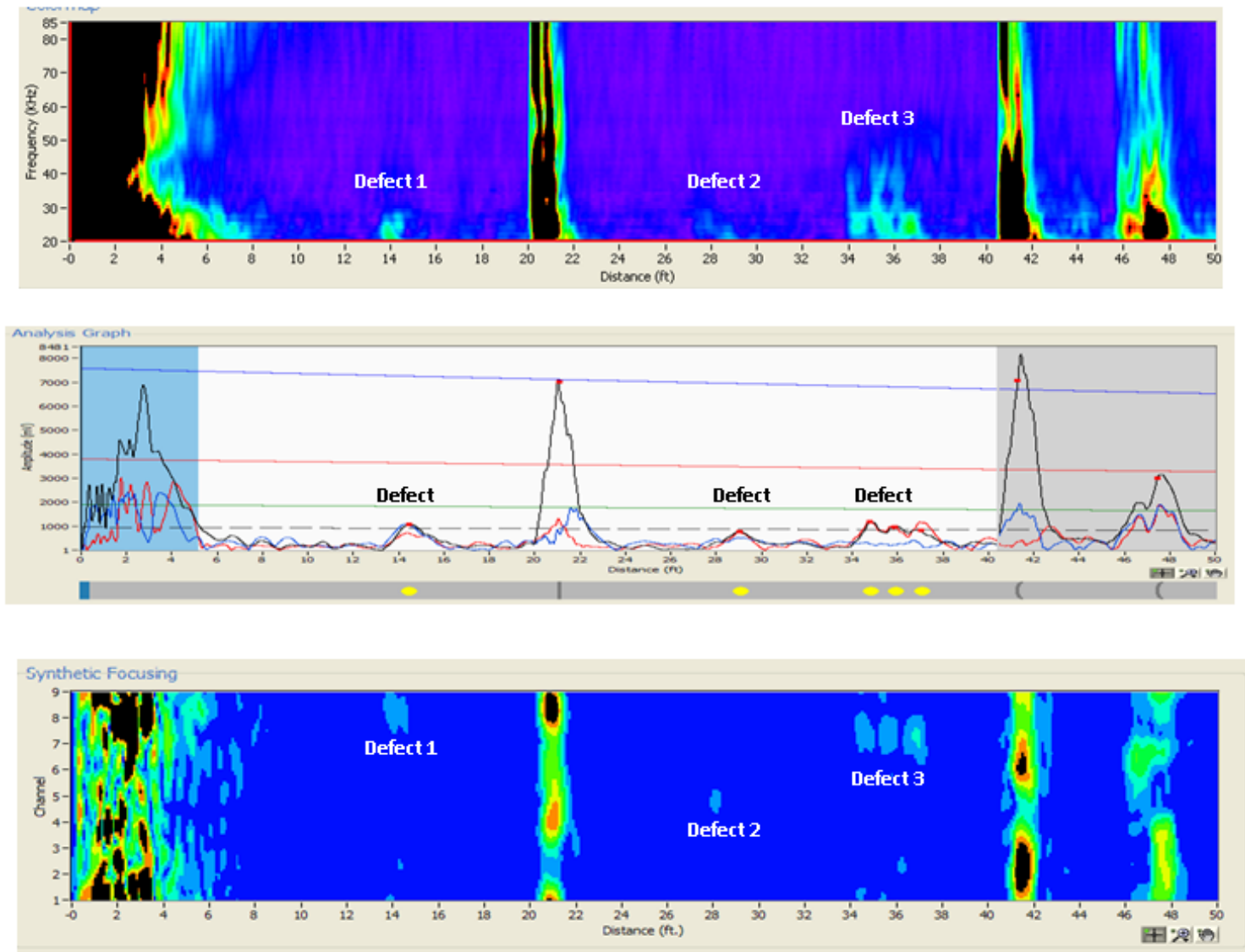

Figure 10

Fast frequency analysis [FFA], envelope, and synthetic

focusing result after examining the pipe section in Figure 9 


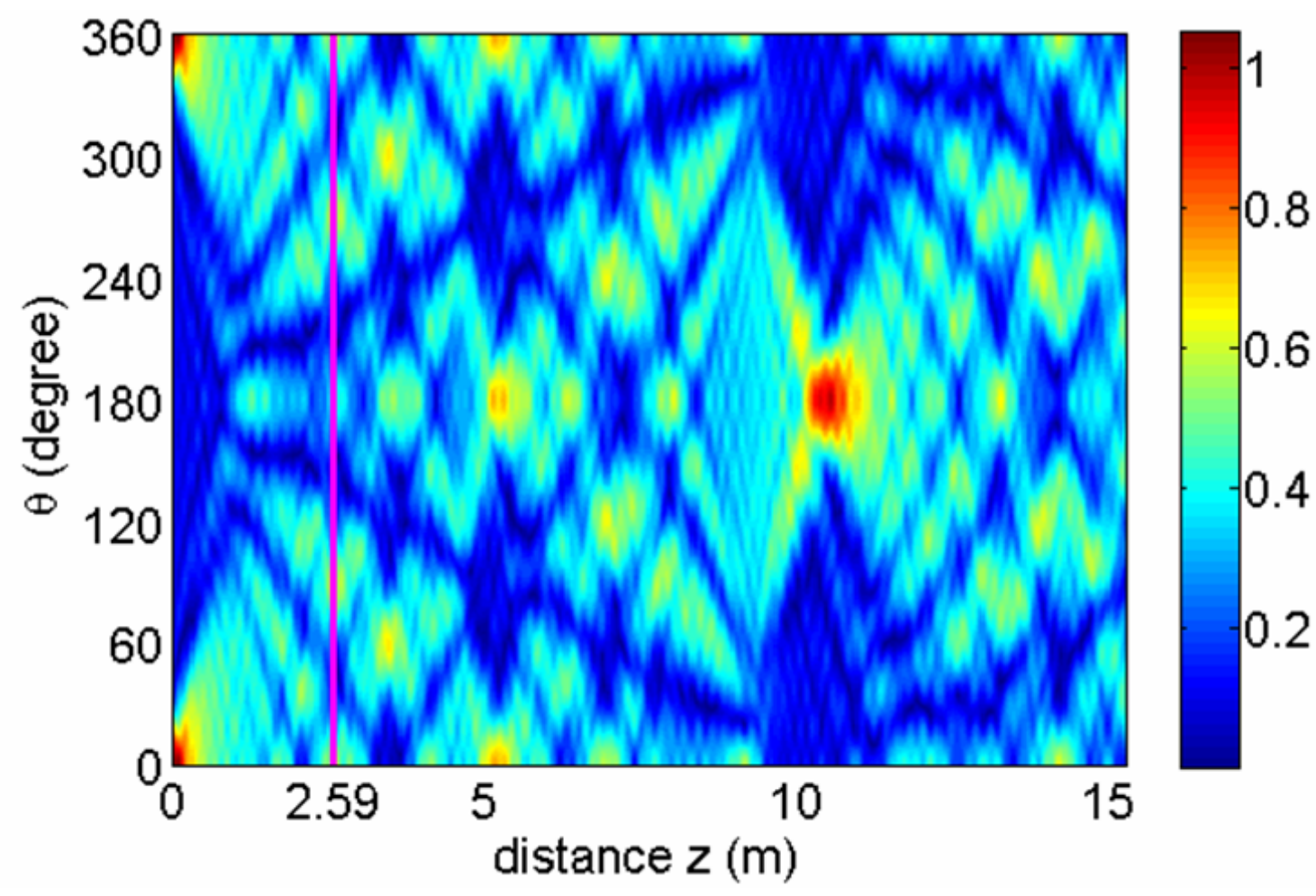

Figure 11

Guided wave displacement interference pattern in an 8 in. schedule 40 steel pipe (unwrapped). The waves were generated by a $45^{\circ}$ source loading vibrating in the circumferential direction at $80 \mathrm{kHz}$.

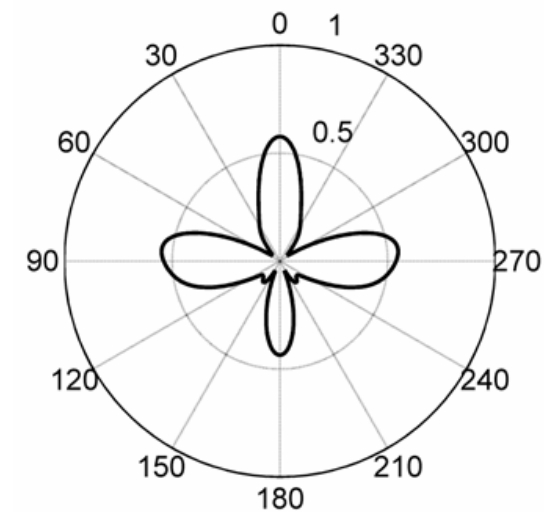

(a). Partial loading angular profile

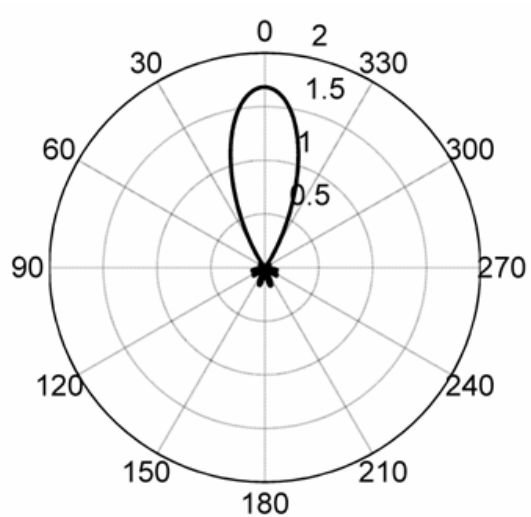

(b). focused profile

Figure 12 Pipe active focusing concept 


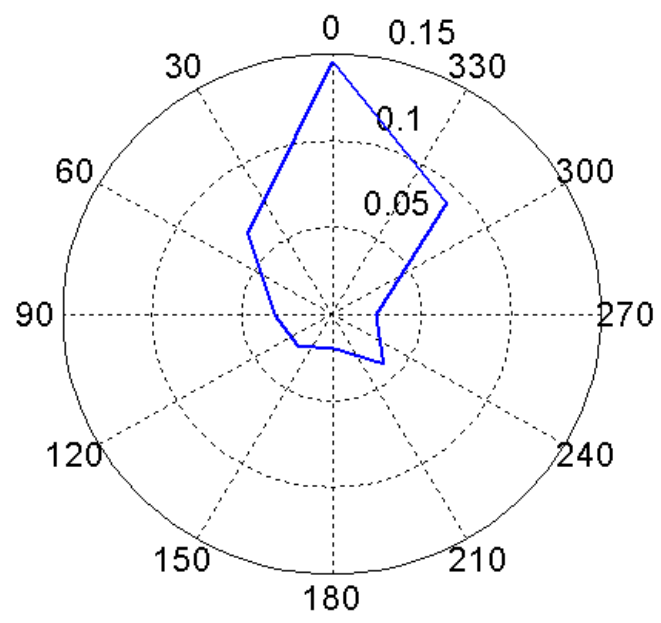

(a). Response from actively focusing around the saw cut distance.

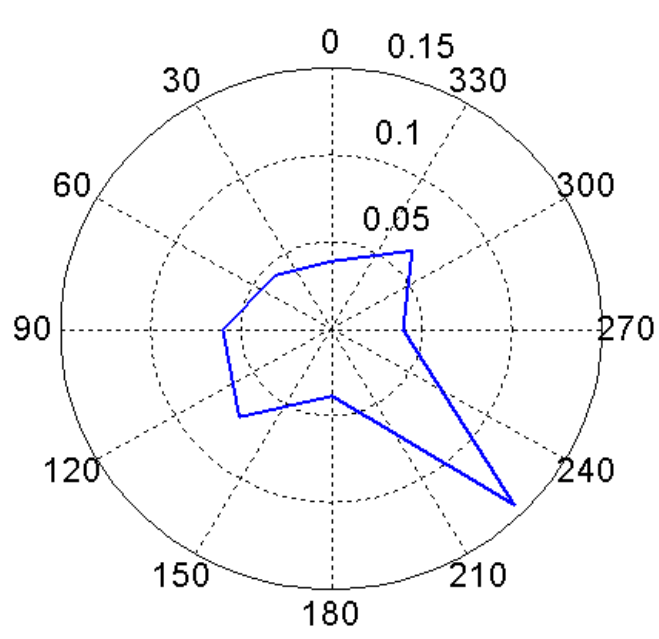

(b). Response from actively focusing around the cluster hole distance.

Figure 13

Active focusing results from pipe end $A$ at $65 \mathrm{kHz}$

\section{$\underline{\text { Rail }}$}

Guided waves are also finding increased use in a variety of different rail inspection applications. See Lee et al [43] for an example. We'll consider here the ability to cover various portions of a rail, from head, to web, to base in this brief discussion. The dispersion curves for a rail are close together, and in fact almost covers the entire phase velocity dispersion curve space except for bounds, as an example on the lower end where we only propagate a pseudo-Rayleigh surface wave mode. Despite the complexity, the curves are useful. Wave structures variations occur from one region to another in the dispersion curve space. It becomes possible with the appropriate mode and frequency choice to have energy propagate in the head only, or in the entire rail. See a few static shots in figure 14. If transverse crack detection under shelling was a goal, the energy in head only example would work well. If you were seeking a solution to find a base defect, complete rail coverage would be useful. See [43] for details. 


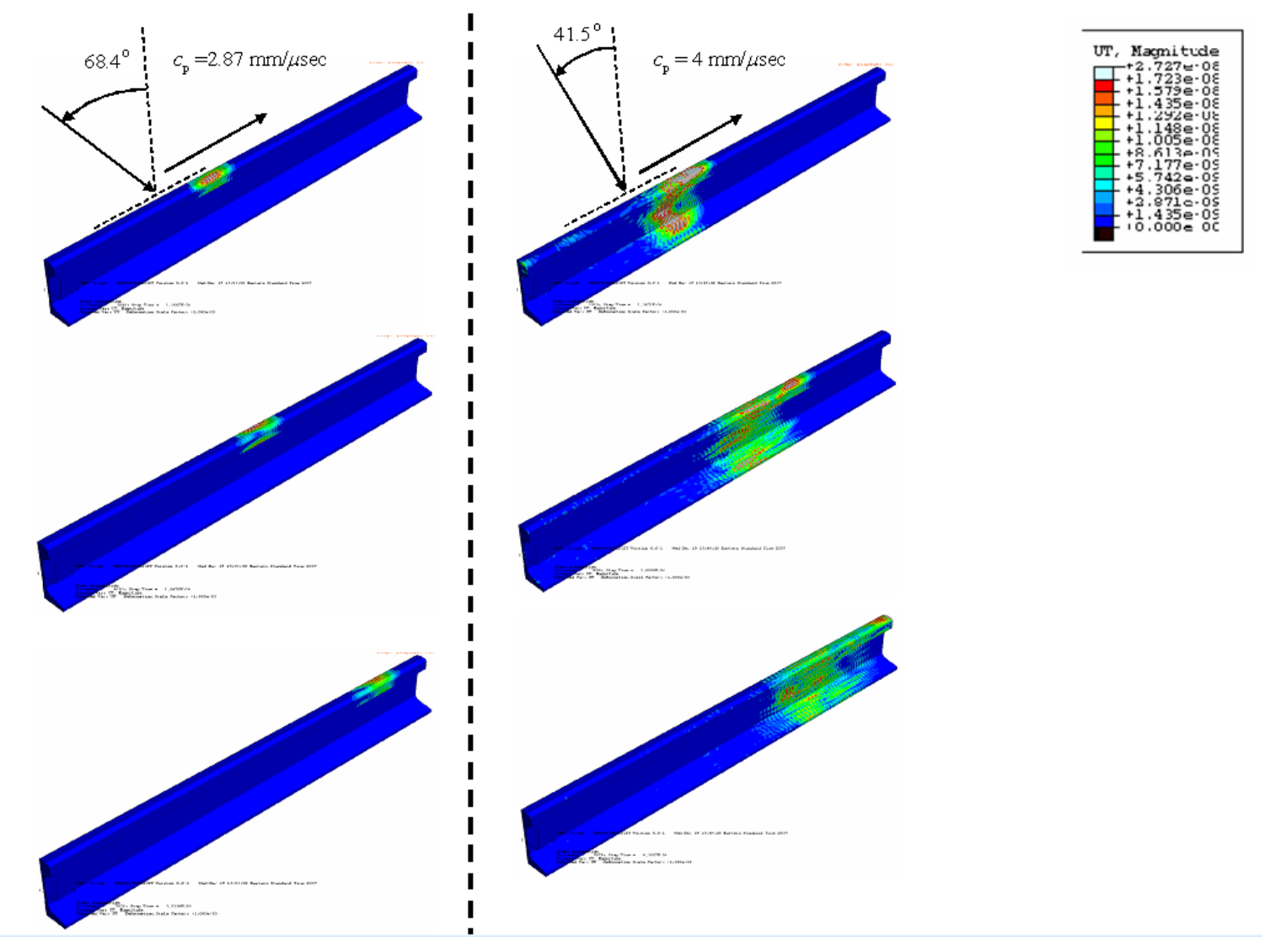

Figure 14

Rail coverage as a function of mode selection

\section{Bonding and Composites}

Mode and frequency selection are also useful when solving inspection problems with bonding situations for composite materials. Let's consider the inspection of a titanium repair patch bonded to an aluminum structure on an aircraft. If we were to find an interface weakness or a kissing bond, guided waves would be useful as we could get a dominant in-plane displacement component into the interface which from earlier work we know would be sensitive to the weak interface. To do this, consider the dispersion curve for the titanium to aluminum bonded structure as calculated in figure 15.

Superimposed on the curves is the magnitude of the in-plane displacement component. Red areas, for example, point to good portions of the curve to carry out an inspection. Of the possibilities, consider the source influence study depicted in figure 16. The mode selected is somewhat separated from the others, and can easily be generated with an actuator havving a narrow phase velocity spectrum and frequency spectrum. An angle beam piezoelectric sensor or a comb type piezoelectric or EMAT activation could be designed for the inspections. See Puthillath et al.[49] for details. 


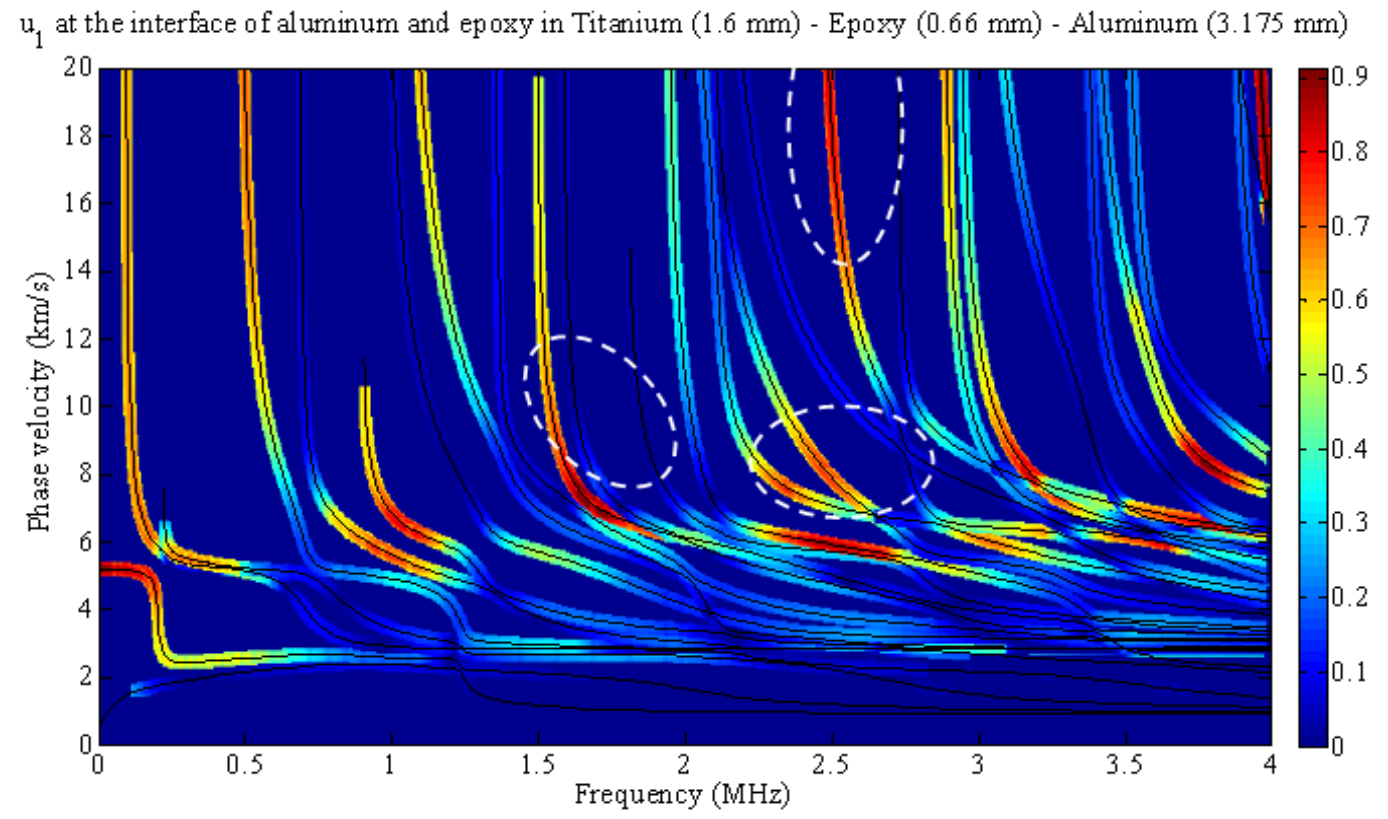

Figure 15

Interfacial Displacement (in-plane) at Al-epoxy interface in Ti-epoxy-Al specimen

\section{0 degree wedge loading}

Source Influence - Wedge Load: $2.5 \mathrm{MHz}, 5 \mathrm{cy}, 10 \mathrm{deg}$

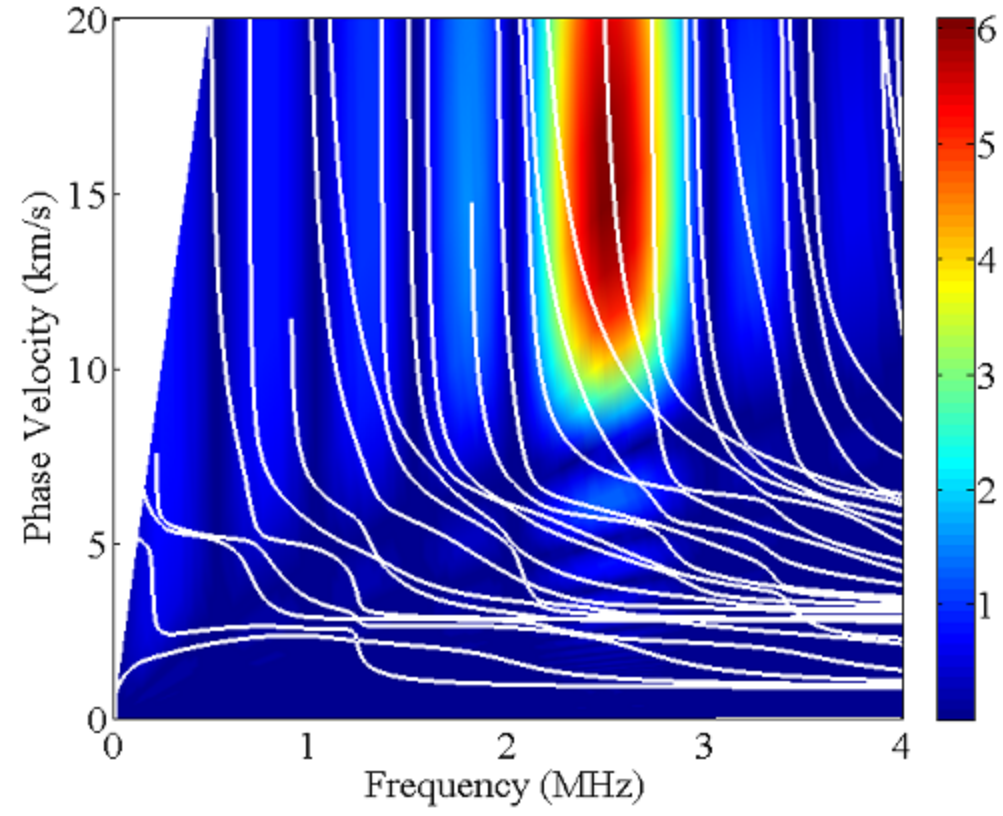

Figure 16

Source-Influence Study of guided wave loading sources 


\section{Imaging and Tomography}

Ultrasonic guided wave tomography with a variety of different sensor distributions on a structure can become a valuable tool in SHM. Success depends, however, on using the right actuators. For example, in the plate with a corrosion defect shown in figure 16, a guided wave tomography experiment was conducted with a set of cylindrically shaped transducers commercially available off the shelf; very poor results were obtained when water was splashed onto the plate. On the other hand, when using a carefully designed set of annular array transducers, excellent results were obtained whether the plate was dry or wet. See figure 17. This is possible by selecting a pint on the phase velocity dispersion curve space with dominant in-plane displacement so that the ultrasonic wave would not leak into the water. The annular array sensor is similar to a comb type transducer and its activation line in the phase velocity dispersion curve space can intersect the optimal text point.

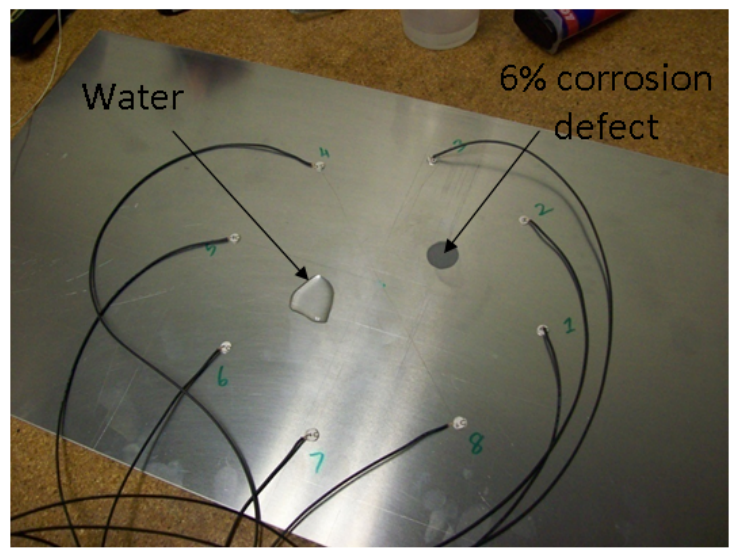

Wet Aluminum Plate with a $6 \%$ corrosion defect

Poor Results

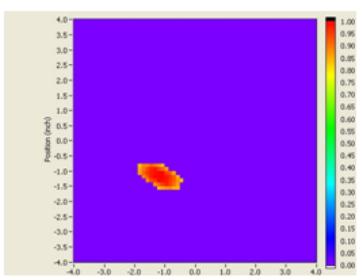

Tomogram obtained $350 \mathrm{KHz}$

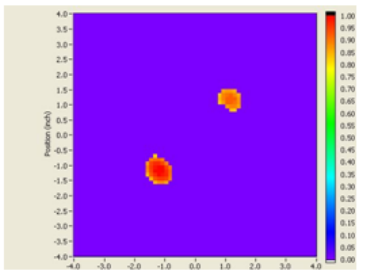

Tomogram obtained $1.05 \mathrm{MHz}$

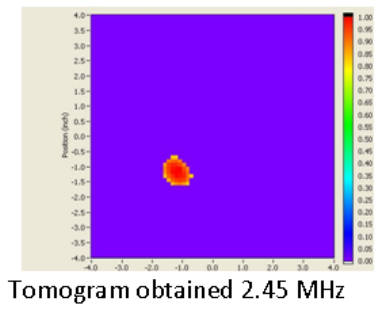

Water only

Corrosion and Water

Water only

Figure 16

Water loaded plate influence 


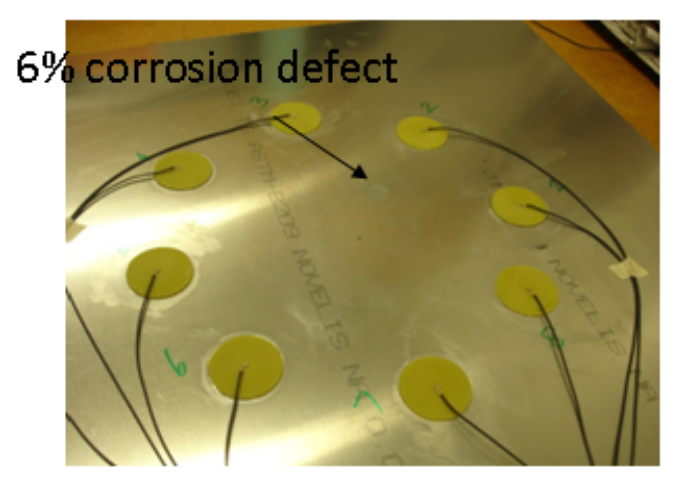

Dry Aluminum Plate with a $6 \%$ corrosion defect

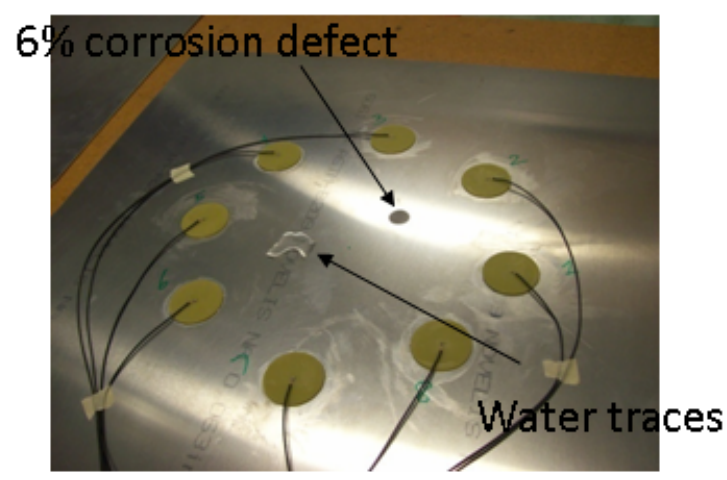

Wet Aluminum Plate with a $6 \%$ corrosion defect

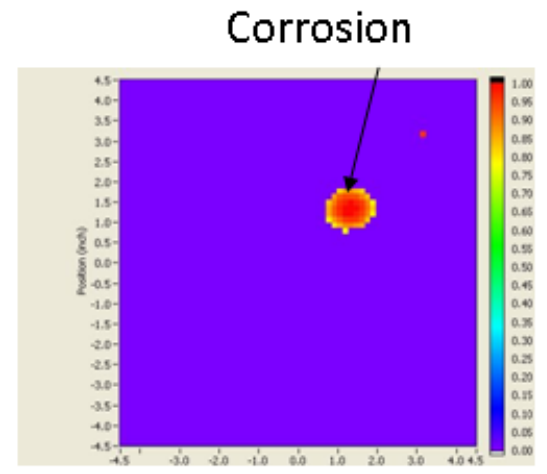

Tomogram obtained with S1 mode at $2.4 \mathrm{MHz}$

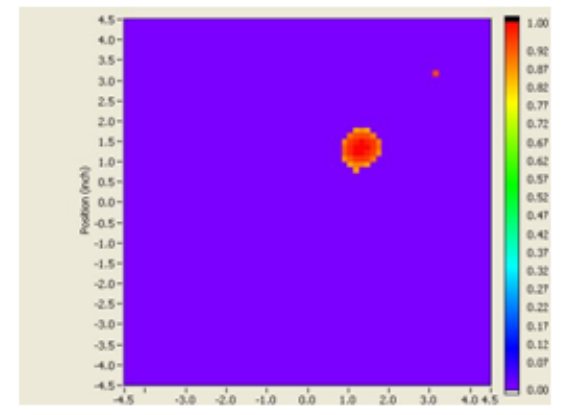

Tomogram obtained with S1 mode at $2.4 \mathrm{MHz}$

Figure 17

Corrosion detection with annular array sensors

\section{Phased array for plate}

Phased array application is now going beyond medical and ultrasonic bulk wave phased arrays, to guided wave phased arrays for pipe, and now to guided wave phased arrays for plates. A simulation of a radar like scan is simulated in figure 18 with static shot shown at 7 positions. Proper sensor design is required to do this from a small circular array of sensors at the center of a plate. Keep in mind here that appropriate mode and frequency control is also necessary in order to optimize defect detection sensitivity, to scan a composite plate, and to overcome skew angle and group velocity variation in the plate. Multiple scans might be necessary. Some of the challenges in moving this method forward are outlined in table 8. 
$0.0^{\circ}$
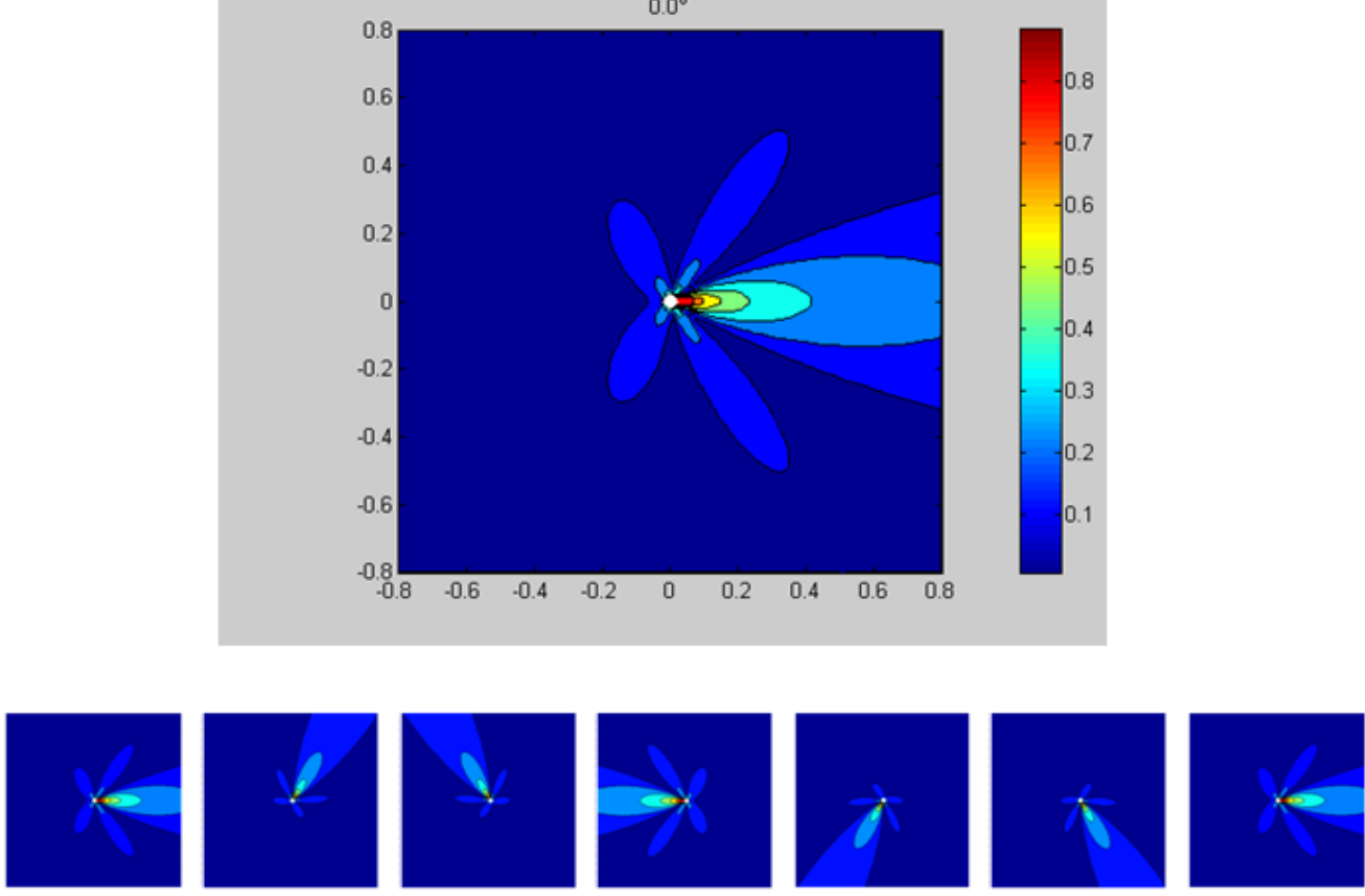

Notes: Guided wave beam can be steered into

different directions by applying phase delays to the elements of an array, circular array example.

\section{Figure 18}

Ultrasonic Guided Wave Beam Steering Using Phased Arrays 


\section{Table 8}

Guided wave phased array technical challenges and solutions

Technical Challenges

-Multi-modes application environment

-Guided Wave Dispersion

-Skew effects in anisotropic plates
Solutions

-Guided wave transducer design and mode tuning to achieve single mode excitation and detection ([Giurgiutiu, et al], [Raghavan and Cesnik], (Rose, et al])

-Wave number/frequency domain beam steering ([Wilcox],[Ruzzene])

-Select a guided wave mode and frequency that is insensitive to the material anisotropy

\section{Ultrasonic Vibrations}

A new ultrasonic guided wave method to provide a robust signature of a structure has recently been introduced by Rose et al [64]. This technique bridges the gap from transient high frequency guided wave analysis to more traditional low frequency ultrasonic model analysis. The characteristics of the methods are presented in table 9. The high frequency ultrasonic modal patters or ods depends on the ultrasonic loading function. Sensitivity optimization is possible here, again, by selecting the proper mode and frequency for the phase velocity dispersion curve space. This approach is particularly useful in manufacturing hundreds of a complex shaped part and follow up later in service. 
Table 9

A short comparison of ultrasonics, model analysis, and UMAT techniques

\begin{tabular}{|c|c|c|c|}
\hline & Defect detection size & Sender positions & Speed \\
\hline $\begin{array}{c}\text { Ultrasonic Guided } \\
\text { Wave }\end{array}$ & Very small $\sqrt{ }$ & Many X & Slow X \\
\hline $\begin{array}{c}\text { Vibration Modal } \\
\text { Analysis }\end{array}$ & Large X & One $\sqrt{ }$ & Fast $\sqrt{ }$ \\
\hline UMAT & Small to intermediate $\sqrt{|c|}$ & One $\sqrt{ }$ & Fast $\sqrt{\text { good news, } X \text { bad news }}$ \\
\hline
\end{tabular}

\section{Ultrasonic Modal Analysis Technique (UMAT)}

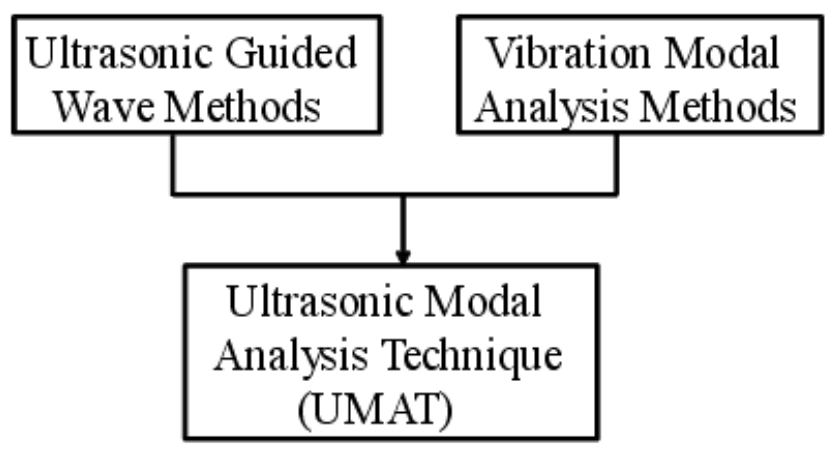

Block diagram associated with Table 9 


\section{Other}

Guided wave innovation goes beyond application in NDE and SHM. For example, it is shown by Zhu et al [67] that selection of a suitable wave structure, hence mode and frequency, which then can fracture/delaminate a layer or patch of ice from a substrate. Guided waves can also be used in ice detection. See [2]. The same principle can be extended to gas entrapment detection in a pipeline by measuring guided wave energy transferred from one position in a pipeline to another. Again, the right mode and frequency must be selected to ensure success so that appropriate amounts of ultrasonic energy can leak into the fluid, but will certainly not leak into the gas entrapment regions.

\section{Concluding Remarks}

Advances in guided wave understanding and computational power are making guided wave inspections a reality today. Of particular significance are applications in aircraft, pipelines, rail and bridges.

New directions point to NDE and SHM with inexpensive distributive sensor networks and sparse arrays for a line of sight analysis,tomography, phased array work, and ultrasonic vibration. Besides defect detection and location analysis for screening, new work also points to more detailed quantitative characterization analysis

Guided wave innovation can go beyond application in NDE an SHM. Examples in ice detection, de-icing, and gas entrapment detection were cited.

For successes and challenges in ultrasonic guided applications to date, see Rose [74]

\section{References}

1. Graff, K.F., Wave Motion in Elastic Solid, Oxford University Press, 1975.

2. J.L. Rose, Ultrasonic Waves in Solid Media, Cambridge University Press, 1999.

3. Achenbach, J.D., Wave Propagation in Elastic Solids, Elsevier Science, Amsterdam, 1973.

4. Auld, B.A., Acoustic Fields and Waves in Solids, John Wiley and Sons, 1973 (Reprinted R.E. Krieger Publ. Co., Malabar, Florida, 1990).

5. Datta, S.K., Shah, A.H., Elastic Waves in Composite Media and Structures: With Applications to Ultrasonic Nondestructive Evaluation, CRC Press, 2008.

6. Achenbach, J.D., Reciprocity in Elastodynamics, Cambridge University Press, 2003.

7. Rokhlin, S.I., Chimenti, S.E., Nagy, P.B., Physical Ultrasonics of Composites, Oxford University Press, 2011.

8. Rose, J.L., Ditri, J., Pilarski, A., "Wave Mechanics Principles in Acousto-Ultrasonic NDE", Journal of Acoustic Emission, Vol. 12, Nos 1/2, pg. 23-26, 1994.

9. Zhu, W., Rose, J.L., "Lamb Wave Generation and Reception with Time-Delay Periodic Linear Arrays: A BEM Simulation and Experimental Study", IEEE Transactions on Ultrasonics, Ferroelectrics and Frequency Control, Vol. 46, No. 3, pgs. 654-664, May 1999. 
10. Gao, H., Rose, J.L., "Goodness dispersion curves for ultrasonic guided wave based SHM: a sample problem in corrosion monitoring", The aeronautical journal of the royal aeronautical society, v 114 , Jan. 2010.

11. Yan, F., Qi, X., Rose, J.L., and Weiland, H., "Ultrasonic Guided Wave Mode and Frequency Selection for Defect Detection and Characterization in a Multilayer Hybrid Laminate," Materials Evaluation, Vol. 68, No. 2, pp. 169-175, 2010.

12. Fromme, P., Sayir, M.B., "Detection of cracks at rivet holes using guided waves", Ultrasonics, v 40, n 1-8, p 199-203, May 2002.

13. Rizzo, P., Cammarata, M., Dutta, D., Sohn, H., Harries, K., "An unsupervised learning algorithm for fatigue crack detection in waveguides", Smart Materials and Structures, v 18, n 2, p 025016 (11 pp.), Feb. 2009.

14. Ing, R.K., Fink, M., "Time-reversed Lamb waves", IEEE Transactions on Ultrasonics, Ferroelectrics and Frequency Control, v 45, n 4, p 1032-43, July 1998.

15. Wilcox, P.D., "A rapid signal processing technique to remove the effect of dispersion from guided wave signals", IEEE Transactions on Ultrasonics, Ferroelectrics and Frequency Control, v 50, n 4, p 419-27, April 2003.

16. Rose,J. L.,Ditri,J.J.,Pilarski,A.,Rajana,K.M.,and Carr,F.T. (1993). A guided wave imspection technique for nuclear steam generator tubing," NDT\&E Int, vol. 27(6), pp 307-310

J. J. Ditri and J. L. Rose, "Excitation of guided elastic wave modes in hollow cylinders by applied surface tractions," J. Appl. Phys., Vol. 72, Issue 7, pp. 2589-2597, 1992.

17. J. Li and J. L. Rose, "Excitation and Propagation of Non-axisymmetric guided waves in a Hollow Cylinder", J. Acoust. Soc. Am., Vol.109, Issue 2, pp. 457-464, 2001.

18. J. Li and J. L. Rose, "Angular-profile tuning of guided waves in hollow cylinders using a circumferential phased array", IEEE Trans. Ultrason., Ferroelect., Freq. Contr., Vol. 49, Issue 12, pp.1720-1729, 2002.

19. Rose, J.L., Mudge, P.J., "Flexural Mode Focusing in Pipe," 8th European Conference on Non-Destructive Testing, Barcelona, Spain, June 17-21, 2002.

20. Z. Sun, L. Zhang, B.J. Gavigan, T. Hayashi, and J. L. Rose, "Ultrasonic flexural torsional guided wave pipe inspection potential", ASME Proceedings of Pressure Vessel and Piping Division Conference, PVP- 456, pp.29-34, 2003.

21. Z. Sun, L. Zhang and J.L. Rose, "Flexural Longitudinal and Torsional Modes Natural Focusing Phenomena in a Pipe," Proceedings of QNDE, Vol. 23, pp.193-197, 2003.

22. Rose, Joseph L., Sun, Zongqi, Mudge, Peter J., Avioli, Michael J., "Guided wave flexural mode tuning and focusing for pipe testing", Materials Evaluation, v 61, n 2, p 162-167, February 2003.

23. Thompson, R.B., Alers, G.A., Tennison, M.A. , "APPLICATION OF DIRECT ELECTROMAGNETIC LAMB WAVE GENERATION TO GAS PIPELINE INSPECTION", Conference: IEEE Ultrason Symp, Proc, pp 91-94, October 4, 1972 - October 7, 1972.

24. Van Velsor, J.K, Rose, J.L., and Nestleroth, J.B., "Enhanced coating disbound detection capabilities in pipe using circumferential shear horizontal guided waves," Materials Evaluation, v 67, n 10, p 11791188, 2009.

25. Hayashi, T. and Murase, M., "Defect imaging with guided waves in a pipe," J. Acoust. Soc. Am., vol.117, pp. 2134-2140, 2005.

26. Mu, J. and Rose, J.L., "Long range pipe imaging with a guided wave focal scan," Materials Evaluation, vol. 66(6), pp. 663-666, 2008.

27. $\mathrm{Mu}, \mathrm{J}$. and Rose, J.L., "Guided wave propagation and mode differentiation in hollow cylinders with viscoelastic coatings," J. Acoust. Soc. Am., v. 124(2), pp. 866-74, 2008. 
28. Davies, J. and Cawley, P., "The application of synthetic focusing for imaging crack-like defects in pipelines using guided waves," IEEE Trans. Ultrason., Ferroelect., Freq. Contr., vol. 56, no. 4, pp. 759771, 2009.

29. Mu, J., Zhang, L., and Rose, J.L., "Pipe inspection with guided wave synthetic focusing technique," Materials Evaluation, v 68, n 10, p 1171-1176, 2010.

30. Velichko, A. and Wilcox, P.D., "Post-processing of guided wave array data for high resolution pipe inspection," J. Acoust. Soc. Am., 126(6), pp.2973-2982, 2009.

31. Pavlakovic, B., Lowe, M., Alleyne, D., Cawley, P., "DISPERSE: a general purpose program for creating dispersion curves", Review of Progress in Quantitative Nondestructive Evaluation, p 185-92 vol.1, 1997.

32. Demma, A., Cawley, P., Lowe, M.J.S., "Mode conversion of longitudinal and torsional guided modes due to pipe bends", AIP Conference Proceedings, n 557A, p 172-9, 2001.

33. Ma, J., Lowe, M.J.S., Simonetti, F., "Feasibility study of sludge and blockage detection inside pipes using guided torsional waves", Measurement Science and Technology, v 18, n 8, p 2629-2641, August 1, 2007.

34. Hayashi, T., Kawashima, K., Sun, Z., Rose, J.L., "Analysis of Flexural Mode Focusing by a Semianalytical Finite Element Method," Journal of Acoustical Society of America, 113, pp. 1241-1248, 2002.

35. Kwun, H., Dynes, C., "Long-range guided wave inspection of pipe using the magnetostrictive sensor technology - Feasibility of defect characterization", Proceedings of SPIE - The International Society for Optical Engineering, v 3398, p 28-34, 1998.

36. Kim, Y.Y., Park, C.I., Cho, S.H., Man, S.W., "Torsional wave experiments with a new magnetostrictive transducer configuration", Journal of the Acoustical Society of America, v 117, n 6, p 3459-3468, June 2005.

37. Grewal, D. S., "Improved Ultrasonic Testing of Railroad Rail for Transverse Discontinuities in the Rail Head Using Higher Order Rayleigh (M21) Waves," Mater. Eval., 54, pp. 983-986, 1996.

38. Hayashi, T., Song, W., Rose, J.L., "Guided wave dispersion curves for a bar with an arbitrary crosssection, a rod and rail example", Ultrasonics, Volume 41, Issue 3, pp.175-183, May 2003.

39. Wilcox, P. D., Pavlakovic, B. N., Evans, M. J., Vine, K. A., Cawley, P., Lowe, M. J. S. and Alleyne, D. N., "Long Range Inspection of Rail Using Guided Waves" in Review of Progress in Quantitative NDE, vol. 22, pp. 236-243, 2003.

40. Gunawan, A., Hirose, S., "Boundary element analysis of guided waves in a bar with an arbitrary crosssection", Engineering Analysis with Boundary Elements, v 29, n 10, p 913-924, October 2005.

41. Bartoli, I., Marzani, A., Lanza di Scalea, F., Viola, E., "Modeling wave propagation in damped waveguides of arbitrary cross-section", Journal of Sound and Vibration, v 295, n 3-5, p 685-707, August 22, 2006.

42. Lee, C.Y., Rose, J.L, Cho, Y., "A guided wave approach to defect detection under shelling in rail", NDT \& E International, Volume 42, Issue 3, pp.174-180, April 2009.

43. Mal, A.K., Xu, P., Bar-Cohen, Y., "Ultrasonic nondestructive evaluation of adhesive bonds", American Society of Mechanical Engineers, Materials Division (Publication) MD, v 9, p 85-89, 1988.

44. Chimenti, D.E., Nayfeh, A.H., "Experimental ultrasonic reflection and guided wave propagation in fibrous composite laminates", American Society of Mechanical Engineers, Applied Mechanics Division, AMD, v 90, p 29-37, 1988.

45. Datta, S.K., Shah, A.H., Karunasena, W., "Edge and layering effects in a multilayered composite plate", Computers and Structures, v 37, n 2, p 151-162, 1990.

46. Na, W., Kundu, T., Ehsani, M.R., "Ultrasonic guided waves for steel bar concrete interface testing", Source: Materials Evaluation, v 60, n 3, p 437-444, 2002.

47. Hosten, B., Castaings, M., "Finite elements methods for modeling the guided waves propagation in structures with weak interfaces", Journal of the Acoustical Society of America, v 117, n 3, p 1108-13, March 2005. 
48. Puthillath, P. and Rose, J.L., "Ultrasonic guided wave inspection of a Titanium patch bonded to an Aluminum aircraft skin," International Journal of Adhesion and Adhesives, v. 30, pp. 566-573, 2010

49. Li, J. and Rose, J.L., "Implementing Guided Wave Mode Control by Use of a Phased Transducer Array," Ultrasonics, Ferroelectrics \& Frequency Control, Vol. 48, No. 3, pp. 761-768, May 2001.

50. Giurgiutiu, V., Bao, J., "Embedded ultrasonic structural radar with piezoelectric wafer active sensors for the NDE of thin-wall structures", ASME International Mechanical Engineering Congress and Exposition, Proceedings, p 31-38, 2002.

51. Wilcox, P.D. , "Omni-Directional Guided Wave Transducer Arrays for the Rapid Inspection of Large Areas of Plate Structures," IEEE Trans. Ultrason., Ferroelect., Freq., v 50(6), pp 699-709., 2003.

52. Yan, F. and Rose, J.L., "Guided Wave Phased Array Beam Steering in Composite Plates", Proc. SPIE 6532: 65320G, 2007.

53. Yan, F. and Rose, J.L., "Time Delay Comb Transducers for Aircraft Inspection", The Aeronautical Journal of the Royal Aeronautical Society, 113(1144), pp. 417-427, 2009.

54. Salas, K.I., Cesnik, C.E.S., "Guided wave structural health monitoring using CLoVER transducers in composite materials", Smart Materials and Structures, v 19, n 1, 2010.

55. Senesi, M., Xu, B., Ruzzene, M., "Experimental characterization of periodic frequency-steerable arrays for structural health monitoring", Smart Materials and Structures, v 19, p 055026 (11 pp.), April 2010.

56. Hinders, M.K., Malyarenko, E.V., McKeon, J.C.P., "Ultrasonic Lamb wave tomographic scanning", Proceedings of SPIE - The International Society for Optical Engineering, v 3586, p 279-291, 1999.

57. Gao, H., Shi, Y., Rose, J.L., "Guided Wave Tomography on an Aircraft Wing with Leave in Place Sensors", REVIEW OF PROGRESS IN QUANTITATIVE NONDESTRUCTIVE EVALUATION, v. 760, pp. 1788-1794, 2005.

58. Breon, L.K, Van Velsor, J.K., and Rose, J.L., "Guided wave damage detection tomography for structural health monitoring in critical zones of pipelines", Materials evaluation, v. 65, pp. 1215-1219, 2007.

59. Van Velsor J K, Gao H and Rose J L, Guided-wave tomographic imaging of defects in pipe using a probabilistic reconstruction algorithm, Insight: Non-Destructive testing and condition Monitoring, 49(9) (2007) pp. 532-537.

60. Fei Yan, Joseph L. Rose, and Roger L. Royer Jr., "Ultrasonic guided wave imaging techniques in structural health monitoring", Journal of Intelligent Material Systems and Structures, Vol. 21, No. 3, 2010: 377384.

61. Ruzzene, M., "Frequency wavenumber domain filtering for improved damage visualization," Smart Materials and Structures, Vol. 16, No. 6, pp 2116 - 2129, 2007.

62. Hall, J.S., Michaels, J.E.," Computational efficiency of ultrasonic guided wave imaging algorithms", IEEE Transactions on Ultrasonics, Ferroelectrics, and Frequency Control, v 58, n 1, p 244-248, January 2011.

63. Rose, J.L., Yan, F., and Zhu, Y., "Ultrasonic Guided Wave Modal Analysis Technique(UMAT) for Defect Detection," Proceedings of IMAC XVIII, Jacksonville, FL, Feb. 2010.

64. Yan, F. and Rose, J.L., "Defect detection using a ultrasonic guided wave modal analysis technique (UMAT)," Proceedings of SPIE, Vol. 7650, 76500R, 2010.

65. Venna, S., Lin, Y., Botura, G., "Piezoelectric Transducer Actuated Leading Edge De-Icing with Simultaneous Shear and Impulse Forces," Journal of Aircraft, Vol. 44, No. 2, pp. 509-515, 2007.

66. Zhu, Y., Palacios, J.L.; Rose, J.L.; Smith, E.C. , "De-icing of multi-layer composite plates using ultrasonic guided waves", Collection of Technical Papers - 49th AIAA/ASME/ASCE/AHS/ASC Structures, Structural Dynamics and Materials Conference, 2008.

67. Gao H. and Rose J.L., Gao H and Rose J L, "Ice Detection and Classification on an Aircraft Wing with Ultrasonic Shear Horizontal Guided Waves", IEEE Transactions on Ultrasonics, Ferroelectrics, and Frequency Control, v. 56(2), pp. 334-344, 2009. 
68. Michaels, J.E., Cobb, A.C., Michaels, T.E., "A comparison of feature-based classifiers for ultrasonic structural health monitoring", Proceedings of SPIE - The International Society for Optical Engineering, $v$ 5394, p 363-374, 2004.

69. Raghavan, A. and Cesnik, C.E.S., "Modeling of piezoelectric-based Lamb wave generation and sensing for structural health monitoring," Proc. of SPIE, Vol. 5391, pp 419-430, 2004.

70. Cantrell, J.H., Yost, W.T., "Nonlinear ultrasonic characterization of fatigue microstructures", International Journal of Fatigue, V. 23, Supplement 1, pp 487-490, 2001.

71. Kim, J., Jacobs, L.J., Qu, J., "Experimental characterization of fatigue damage in a nickel-base superalloy using nonlinear ultrasonic waves", J. Acoust. Soc. Am., v 120, n 3, 2006

72. Pruell, C., Kim, J.-Y., Qu, J., Jacobs, L.J., "A nonlinear-guided wave technique for evaluating plasticitydriven material damage in a metal plate", NDT\&E International, v 42, n 3, p 199-203, April 2009.

73. J.L. Rose (2010) "Guided Waves Successes and Challenges for Ultrasonic Testing in NDT and SHM", Materials Evaluation, Vol. 68 (5), pp. 495 - 500

\section{$\underline{\text { Acknowledgements }}$}

Thanks are given to my MS and PhD students over the years as well as all of the employees at FBS, Inc for their contributions to the field of ultrasonic guided waves. Cooperation has been a fun and rewarding experience. Thanks also to all of my sponsors over the years and many worldwide friends and colleagues in ultrasonics. 